\title{
Using the Web to Enable Industry-University Collaboration: An Action Research Study of a Course Partnership
}

\section{Ned Kock Department of MIS, Temple University}

Kock@ijoda.cis.temple.edu

\author{
Camille Auspitz \\ Day \& Zimmermann, Inc. \\ Camilie.AuspitzQdayzim.com
}

\author{
Brad King \\ Day \& Zimmermann, Inc.
}

Brad.King@odayzim.com

\section{Abstract}

This paper discusses a course partnership involving Day \& Zimmermann, Inc. (DZI), a large engineering and professional services company, and Temple University. The course was taught between the months of May and July of 1999 and its main goal was to teach students business process redesign concepts and techniques. These concepts and techniques were used to redesign five business processes from DZI's information technology organization. DZI's CIO and a senior manager, who played the key role of project manager, championed the course partnership. A Web site with bulletin boards, multimedia components and static content was used to support the partnership. The paper investigates the use of Web-based collaboration technologies in combination with communication behavior norms and face-to-face meetings, and its effect on the success of the partnership.

Keywords: Industry-university Collaboration, Process Redesign, Action Research, Course Partnerships, Collaboration Technologies, Computer-Mediated Communication

\section{Introduction}

Industry-university partnerships, particularly those involving research universities, are commonplace and on the rise (Burnham, 1997). They allow industry access to quality research services at subsidized costs as well as to potential future employees while still in their formative years. Universities benefit from such partnerships through research grants that complement dwindling government funding, and student exposure to current "real-world" problems and issues.

Some sectors of the economy are more active than others in research involving industry-university collaboration. The manufacturing sector is arguably the most active. In 1998, the National Coalition for Advanced Manufacturing, based in Washington, D.C., released a report on the topic covering a wide range of industries. The vast majority of the companies surveyed for the report praised the concept and highlighted the crucial importance of industry-university partnerships for

Material published as part of this journal, either on-line or in print, is copyrighted by the publisher of Informing Science. Permission to make digital or paper copy of part or all of these works for personal or classroom use is granted without fee provided that the copies are not made or distributed for profit or commercial advantage AND that copies 1) bear this notice in full and 2) give the full citation on the first page. It is permissible to abstract these works so long as credit is given. To copy in all other cases or to republish or to post on a server or to redistribute to lists requires specific permission and payment of a fee. Contact Editor@inform.nu to request redistribution permission.

competitiveness improvement. One association of manufac- turers in particular, Sematech - made up of companies in the US semiconductor industry, stated that a considerable portion of its membership had been literally rescued from their competitiveness downslide by industry-university research partnerships (Wheaton, 1998).

Irrespective of economic sector or industry, the vast majority of industry-university partnerships are of the research partnership type, which predominantly involves applied firmspecific research. In this type of partnership, funding from the industry partner is received in exchange for "intellectual horsepower" in the form of research services and technology transfer (Hollingsworth, 1998). In science-based fields, universities focus on basic research, and the main interest of industry partners is in the commercial and industrial implications of a scientific project and how they can be taken advantage of by internal research and development departments. In less science-based fields, the solution of technical problems is a major concern of industry. In all fields, the exchange of knowledge in techno-scientific communities is a crucial element of interaction in research partnerships (Meyer-Krahmer, 1998).

A much less common type of industry-university partnership is what we refer here to as a course partnership, which gravitates around a regular university course (or set of courses) rather than a research project or program. In these types of partnerships, the industry partner agrees to sponsor one of more courses in which the students are expected to apply concepts and theory learned in class to the solution of some of the 
industry partner's key problems. Students benefit from the direct contact with the industry they are likely to join after they graduate as well as professional relationships they are able to establish during the course.

This paper discusses a course partnership involving a large engineering and professional services company, and a public university, both headquartered in Philadelphia. An action research study of the course partnership conducted between May and July of 1999 is used as a basis. The main goal of the course was to teach students business process redesign concepts and techniques, which were used to redesign several real processes at the industry partner. One salient aspect of this action research study is the role played by a Web-based collaboration system as a communication hub and information repository during the course partnership, which is investigated in light of previous empirical research and key theories. Like typical action research studies (Checkland, 1991; Lau, 1997; Peters and Robinson, 1984; Winter, 1989; Wood-Harper, 1985), ours aimed at providing a service to the research clients (Jonsonn, 1991; Rapoport, 1970; Sommer, 1994) while at the same time performing an exploratory investigation of the effect of Web-based collaboration technologies on course partnerships. The research clients in question were the students and the industry partner. Also, in line with a subclass of action research, namely participatory action research (Greenwood et al., 1993; Elden and Chisholm, 1993; McTaggart, 1991; Whyte, 1991), one of the research clients, the industry partner, participated actively in the compilation and analysis of the exploratory research data, as well as in the interpretation of the findings, including the writing of this paper.

\section{Obstacles to course partnerships}

The wide proliferation of research partnerships in the US and several other countries (Cabral, 1998; Jones-Evans, 1999; Saegusa, 1997; Wong, 1999) can be explained by the incentives to those who directly participate in the partnership. The benefits for industry partners, faculty and students involved range from knowledge acquisition to financial incentives. Of- ten, research partnerships reward research and development department members with workload reduction, increased productivity and knowledge acquisition. Faculty and students are rewarded with funds to support their research and exposure to industry-specific problems and issues outside the scope of university education.

Course partnerships, on the other hand, often fail to benefit a key group of players - the faculty developing and teaching the courses. Most course partnerships involve the adaptation of existing university programs or the creation of new programs to address the needs of a particular industry or company (Mengoni, 1998). In these "wholesale partnerships", the industry benefits from a university program better tailored to its needs, and the university as a whole from an increase in enrollments. The faculty who teach those courses, however, are rarely provided with any direct incentive to participate in such partnerships, in spite of the extra work required to develop new or adapt existing courses to the new program.

A possible alternative to overcome the barrier above is for universities to stimulate and provide the necessary infrastructure for faculty to lead the development of course partnerships on a course-by-course basis, which could potentially lead to better aggregate results in terms of tailoring courses to industry needs. This new approach could be implemented by supporting the development and teaching of specific courses in close collaboration with industry partners, who would provide funding to compensate faculty for their participation and cover other expenses such as specific equipment and software needed to implement the partnership. Key potential benefits of course partnerships for students and industry partners are listed in Table 1:

Assuming that the problem of lack of direct incentives for faculty is solved, key obstacles to course partnerships still remain. Some of these stem from difficulties in the communication and coordination between industry and university participants. Industry and universities often have different organizational cultures, languages and values, which pose commu-

\begin{tabular}{|l|l|}
\hline Benefits for students & Benefits for industry partners \\
\hline $\begin{array}{l}\text { Putting concepts and theories learned in class in } \\
\text { practice, which adds a new and valuable "real- } \\
\text { world" dimension to the learning process. }\end{array}$ & $\begin{array}{l}\text { Hiring selected students with top potential, and } \\
\text { whose behavior and values match the firm's internal } \\
\text { culture, customer orientation and mission. }\end{array}$ \\
\hline $\begin{array}{l}\text { Experiencing first-hand professional issues in their } \\
\text { chosen fields. }\end{array}$ & $\begin{array}{l}\text { Creating the appropriate climate for change due to } \\
\text { the infusion of new ideas. }\end{array}$ \\
\hline $\begin{array}{l}\text { Establishing company contacts that may lead to } \\
\text { future employment. }\end{array}$ & $\begin{array}{l}\text { Absorbing new concepts and ideas that may be used } \\
\text { to boost competitiveness. }\end{array}$ \\
\hline
\end{tabular}

Table 1: Potential benefits of course partnerships 
nication difficulties. Their members follow different work schedules, are rarely co-located, and have different and sometimes conflicting goals (Brannock, 1998), which create coordination difficulties.

In addition to communication and coordination difficulties, a key obstacle to course partnerships is the extra time commitment required from both industry as well as university participants. It can be inferred from careful inspection of Table 1 that the more company members are directly involved in the partnership, the better. For example, the more company members observe students in action during the course partnership, the more accurate will be the identification of future "stellar" employees. However, work pressures may make it difficult to motivate a critical mass of employees to participate actively. Also, faculty teaching such courses must to be willing to take on heavy project management responsibilities in addition to normal teaching duties (Lee, 1998).

\section{The role of Web-based collaboration technologies}

The deployment of standard Web-based technologies in organizations opened up new opportunities for the development of Web-based systems to support inter-organizational collaboration. Since course partnerships are, by definition, interorganizational initiatives involving at least two different entities, i.e., an industry partner and a university, they are prime candidates for the use of Web-based collaboration technologies. The availability of a common infrastructure, the Internet, allows for fast implementation of low cost Web sites with effective communication support and data centralization features. Such Web sites can potentially be used to overcome several of the obstacles outlined in the previous section in the context of the course partnership discussed in this paper.

As state earlier, the course partnership described here involved the establishment of teams whose main goal was to improve several business processes of the industry partner. For this to happen effectively, both industry partner members and students had to agree on the basic concepts, techniques and language used in process improvement initiatives. In this context, Web-based bulletin boards were seen as likely to be useful complements to face-to-face meetings by allowing participants to conduct part of their interaction in an asynchronous and distribute manner, using standard Web browsers. Previous research suggests that the use of electronic bulletin boards is likely to decrease the amount of time required from each individual member of a process improvement team, without any loss of quality, provided that Web-based interaction is used in combination with face-to-face meetings (Kock, 1999; Kock and McQueen, 1998).

Most process improvement initiatives involve the subsequent phases of process selection, modeling, analysis and redesign
(Davenport, 1993; Davenport and Short, 1990; Hammer and Champy, 1993; Harrington, 1991). Given that progressing through these phases generates a large amount of documentation, another useful function of a Web site would be that of providing a central repository for the documentation generated by process improvement teams. The documentation of a given team could also be made available to all teams, so opportunities for integration of the outcomes from different teams could be identified and taken advantage of.

Finally, the combined use of a Web site for communication and centralized data storage would likely improve coordination of the work of different process improvement teams and reduce the amount of time and effort required for that coordination. The project manager would be able to monitor the progress of each team vis-à-vis the progress of the other teams through the Web site, without having to rely only on timeconsuming face-to-face meetings, and take action when needed. General project instructions and guidelines could be provided once for everyone through a specific area of the Web site, rather than repetitively to each team. The sharing of data among teams would likely enable some teams to avoid mistakes made by other teams, as well as reuse interesting process designs and related ideas.

\section{Action research study: Day \& Zimmer- man, Inc. and Temple University}

This section describes the course partnership and discusses the key role that a Web site has played in the success of the partnership. While this paper has three co-authors, including the instructor who was one of the investigators, this section was written in most part by industry partner co-investigators. It reflects their perceptions of the partnership, which the instructor validated through participant observation and research data analysis (this is mentioned so the reader can better appreciate the narrative). It is clear from this section that several of the expected technology benefits above were realized, but some were not. The next section summarizes and discusses both types of effects as "lessons learned" from the action research study.

\section{Initial contacts and meetings: Do we really want to do this?}

In late April of 1999, the CIO of Day \& Zimmermann, Inc. (DZI) received a letter from the instructor (first author of this paper) inquiring if DZI was interested in partnering with Temple University for a graduate level course in business process redesign with applications of Internet collaboration technologies. From the outset, the CIO seemed to believe that this project would benefit DZI's enterprise IT organization (eIT). A meeting was arranged and the instructor went to DZI's headquarters in Philadelphia to meet with the CIO and his management team. At the meeting the instructor presented 
his ideas about the course partnership and proposed an implementation plan. eIT's management found the idea intriguing. The consensus was that a collaboration of this order presented a number of opportunities as well as a number of obstacles.

eIT had recently gone through a major transformation, which included a Capability Design project. This project involved many eIT employees in various teams that evaluated highlevel processes and designed new processes as a foundation for the newly reorganized unit. The proposed partnership with Temple University was seen as likely to enable eIT to leverage some of the momentum created by the Capability Design project. In addition to gaining valuable process design experience, the eIT employees involved in the Temple project would, working with the student team members, be able to identify real process improvements that could be applied once the course was completed. Temple's offer of evaluating and redesigning tactical level processes was seen as a good complement to the high-level process redesign of the earlier Capability Design project.

The most significant obstacles faced by eIT to the implementation of the course partnership were related to time and resource constraints. In addition, there was some concern about whether the redesigned processes would actually be implemented once the course was over. eIT's management and staff were fully engaged and had little or no spare time in which to fulfill the obligations of this type of project. In response to this concern, the instructor proposed that a Web site be used to support the project as a data repository and communication tool. And since the course was being taught both online and in lectures, and the entire course material was to be posted online (including streamed video-clips of lectures), any eIT employee would be able to take the course online, even if he or she was not able to sit in the face-to-face class meetings. An additional, albeit less tangible benefit was the opportunity for the company to observe and evaluate young talent for potential hire into eIT or DZI. It was determined that the benefits outweighed the drawbacks even when taking into consideration that the redesigned processes may not be implemented. The course partnership was formed.

\section{Selecting projects and defining their scope: Managing expectations}

Several processes within eIT were identified for the project. The following processes were selected jointly by eIT and the instructor: Asset Management, Help Desk Call Response, SLA (Service Level Agreement) Development, New Em- ployee Account Set-up, and Key Person University (KPU). A process owner from within eIT was assigned to each of the selected processes. Each process was then assigned a team of students, who were expected to work closely with the process owner. A key element of this project was the working relationship between the process owners and the student teams. Everyone involved was forced to stretch intellectually, organizationally and socially to coordinate multiple schedules and skills. It was evident from the beginning that some groups would perform at a higher level than others. The instructor cautioned eIT management about setting expectations too high. The goal for the University was to teach the students about process redesign and collaborative work methods. eIT had to understand that even though the project very closely resembled a consulting project, the actual redesign results might not be functional or feasible.

eIT strongly believed that this partnership and the project as a whole would have a higher success rate if the focus remained inside eIT and thus limited the amount of involvement required from other DZI businesses and staff units. eIT also assigned one of its senior managers as a fulltime project manager for the course partnership. This level of commitment on the part of the sponsoring company, as well as the decision to fund the partnership through a cash grant, clearly signaled the significance of the project for both the process owners and the student teams. Temple University provided two technical support specialists who were available to assist both eIT and the student teams with various technical issues that arose during the course.

The overall scope of the course was clearly defined in the course outline. Three reports were to be developed. Report 1 included a contextualized description, model, and list of problems associated with the current process, as well as desired achievements of the redesign. Report 2 included the redesign guidelines used and how they were used, and the redesigned process model. Report 3 consisted of an analysis of three different IT solutions to implement the redesigned process, as well as a cost/benefit analysis and an implementation plan for each solution. Specific requirements for the individual processes varied. Of the five selected processes, all were existing processes within eIT with the exception of the KPU. Therefore, development of the first report for the KPU process team was more complicated because they first had to develop a process that they could then redesign. Some of the processes such as the Help Desk and New Employee Account Set-up required greater involvement from extended team members and eIT customers. 


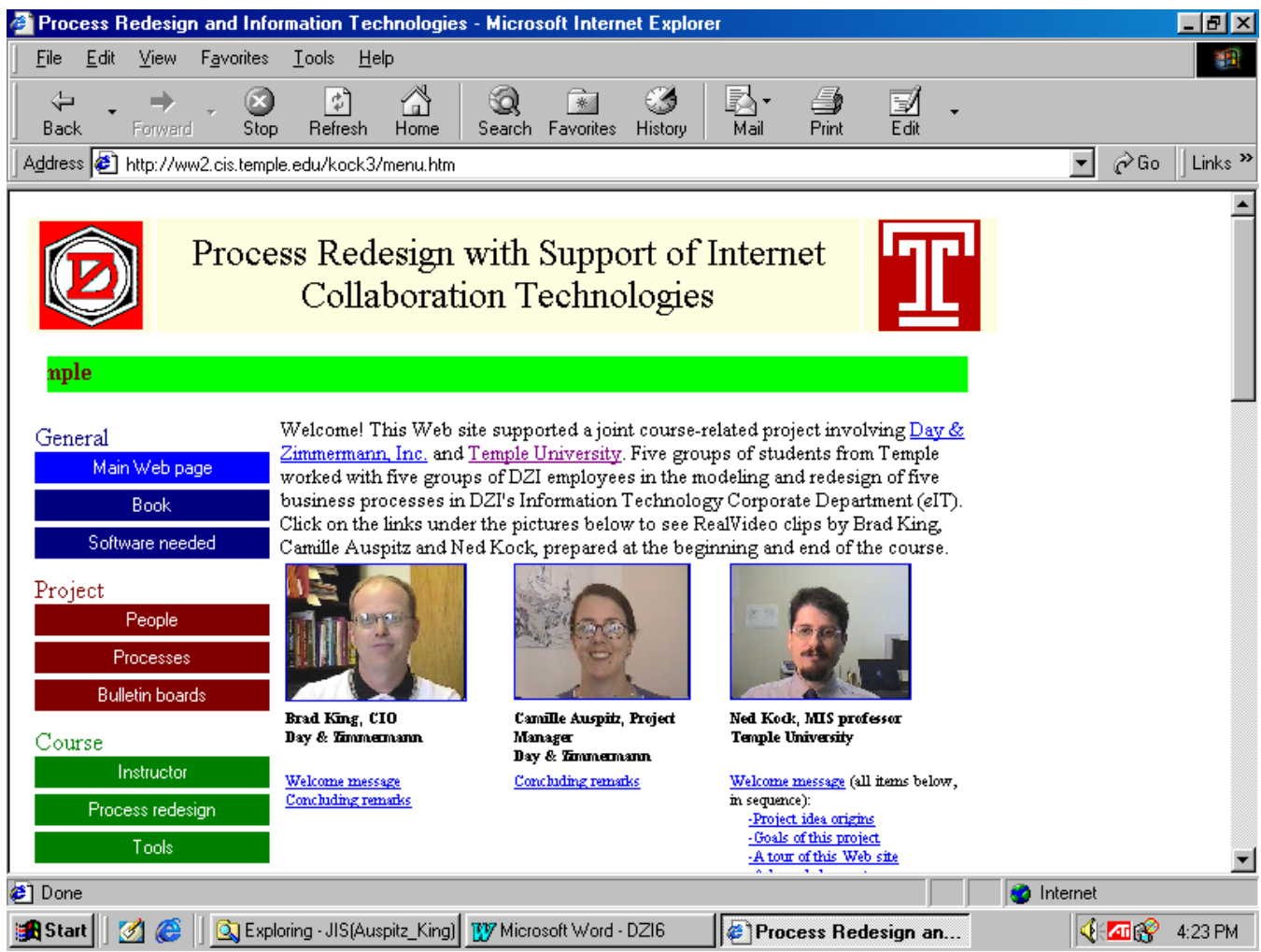

Figure 1: Main page of the Web site

\section{Creating a Web site: Not only a communica- tion tool}

The development of a Web site to support the partnership was a key selling point to eIT from the outset. The instructor created a Web site as the hub of information and collaboration for the course. The Web site contained all the course material, lecture slides, course outline, contact information, pictures and video clips of student teams, discussion threads for each of the processes and a "tools" area that provided detailed tutorials that explained how to create a Web site with similar functionality. It was through this Web site that eIT employees could "attend" the course and all the process team members communicated asynchronously (see Figure 1).

The team members used the discussion threads available on the Web site to post and resolve many issues while working on various draft reports. The process teams met regularly to discuss and review these reports. The Web site enabled all parties involved to access and review draft documents prior to a meeting. Meeting time was therefore maximized and used to discuss modifications to the document content as opposed to being wasted while all present familiarized themselves with a revised document.

It was essential that the skills needed to take advantage of the Web site were developed quickly, which was facilitated by the fact that all features of the Web site required only a standard
Web browser and some free players to be fully utilized. DZI's project manager strongly encouraged all the process owners to access the Web site and review their discussion threads at least twice a day; the instructor did the same for the students. Process owners and student team members were asked to review the progress of the other process teams as well. Each process team developed their own schedule and style to accomplish the requirements of the course. Some teams met weekly; others twice-weekly; others still met only every other week; all with more or less the same level of success in regards to completing the reports.

The Web site was also made available to all eIT employees throughout DZI (over 100 people). While interest and participation from employees not directly involved in the course partnership fell below expected levels, there was enough interest in the technology behind the site to initiate conversations about applying similar technology within the organization. It is essential that diverse IT organizations, such as eIT, share information and collaborate on enterprise issues. Today, well after the course partnership was concluded, eIT has a very active discussion site that addresses numerous topics and issues throughout the organization. While the underlying technology is different, using Lotus Notes and Domino instead of Microsoft FrontPage and Internet Information Server (IIS), the capability is very similar and mirrors that of the Web site developed to support the course partnership. 


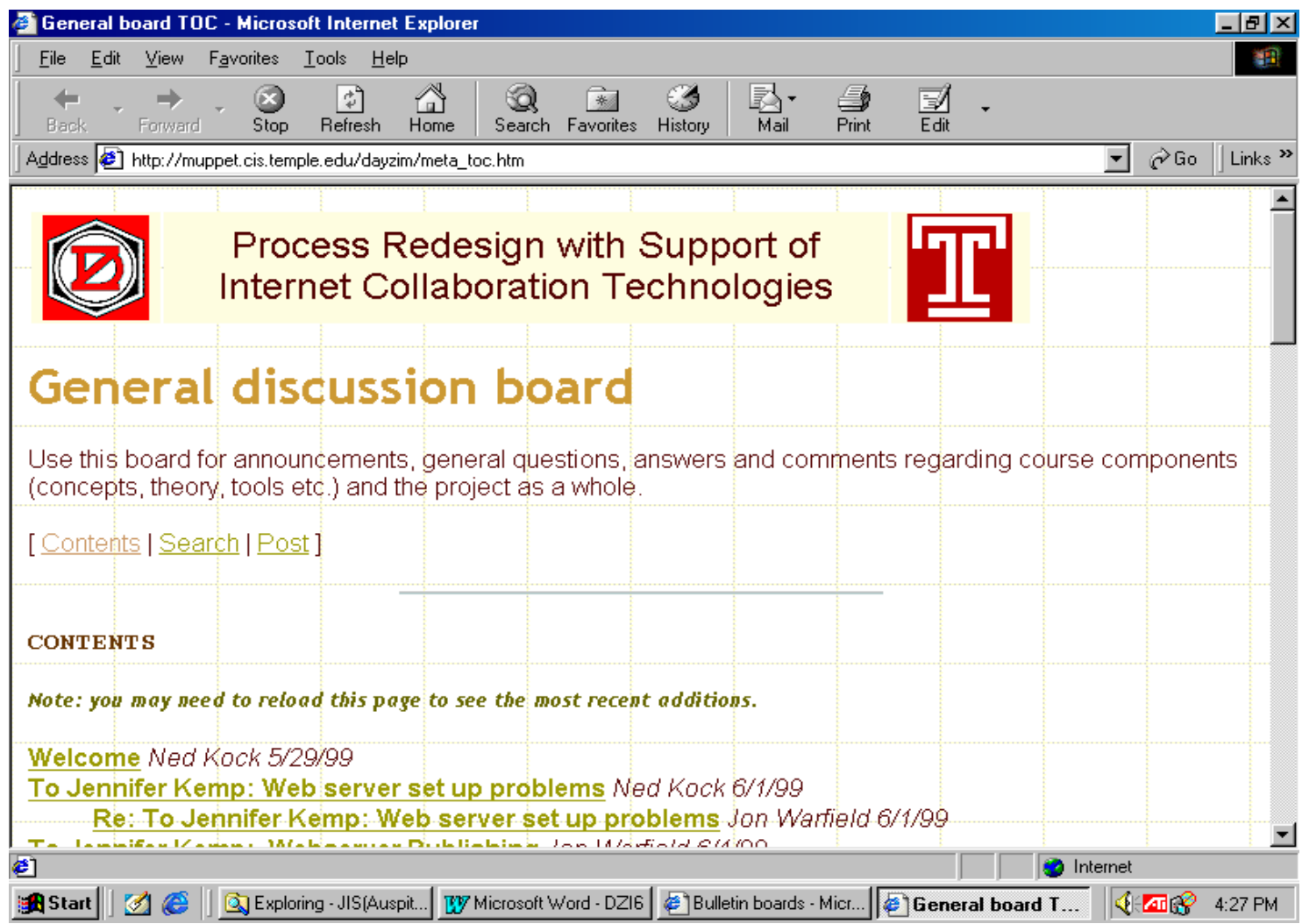

Figure 2: General discussion board for the course partnership (Each process team had its specific discussion board)

\section{Electronic versus face-to-face meetings: Which one to choose and when?}

There were advantages and disadvantages to using Web-based collaboration technologies to address and resolve issues and interact with project team members. The teams were very diverse. Utilizing the online electronic discussions (see Figure 2) was often seen as an effective way to overcome language barriers by formally defining process-specific terms and to clarify issues not properly addressed in face-to-face meetings. In addition, as stated earlier, the ability to maximize precious face-to-face time by enabling all teams members to have access to documentation and discussion topics prior to a meeting was seen as essential. In order to accomplish the objectives of the course, the electronic collaboration capability also enabled team members who were not able to attend a meeting to contribute as well.

However, most participants felt that it was necessary to complement the Web site interaction with face-to-face meetings. From a project management perspective, the face-to-face meetings were seen as particularly effective for building and ensuring consensus. From a corporate standpoint, it was during the face-to-face meetings that the "stellar performers", both students and process owners, could be identified. The same was true for student evaluation from an academic standpoint. While the reports were collaborative efforts and discussions often involved many team members, it was in the meetings and final presentations that the natural leaders and aboveaverage achievers became evident.

\section{Going the extra mile: Project review, pizza party and final presentations}

Throughout the five weeks of the course DZI's project manager provided eIT management with regular status reports summarizing the progress of the various teams. This enabled DZI's CIO to remain up to date as the course progressed. However, the CIO was also interested in the technology used to support the project, the general subject of process redesign, the participation of his staff in the project and what they had learned about their specific processes. In order to provide him with a clearer perspective of his staff's experience, a project review was scheduled in which the eIT process owners would offer the $\mathrm{CIO}$ and an external consultant from the Concours Group a presentation detailing the teams' progress.

The review took place on June 22, 1999 just three days before final reports and final student team presentations were due. Student team members were asked to be present for the review as well. This allowed each presentation to be followed 
by a dynamic discussion between the process owner, student team members, the CIO and the external consultant. These discussions ranged from delving deeper into process descriptions and redesigns to lively forays into technologies' future. A fair amount of time was spent discussing how technology affects business processes and the growing role technology will continue to play in strategic business planning initiatives.

DZI's eIT organization was very satisfied with the progress and outcomes of this collaborative project and was able to demonstrate that enthusiasm by hosting a party following the project review presentations. All the students, process owners, extended team members and eIT management sponsors enjoyed a casual party at a local pizza restaurant. This setting was conducive to informal and lively conversations and made the $\mathrm{CIO}$, the instructor and the external consultant available to many of the project participants. Given that the course had been very intense for all the participants, the gathering also allowed for sharing of personal stories and interests and seemed to have created a relaxed atmosphere and an engaging and satisfying note on which to end the project.

The final presentations took place on the last day of the course and where held in DZI's Boardroom. Each of the student teams prepared a PowerPoint presentation that summarized Reports 1 and 2 and focused on the content of Report 3, which, as mentioned before, consisted of an analysis of IT implementation solutions for the redesigned process, as well as a cost/benefit analysis and implementation plan for each IT implementation solution.

In many of the final presentations the IT solutions in conjunction with the redesigned process were viable when considered independent from one another. What came to light essentially during these presentations was the fact that since all the processes were within the domain of eIT, they were all in some way related. However, the teams had proceeded in an insular manner. Had the connections been identified early on in the project, the teams may have worked together and produced very different findings and recommendations.

Nevertheless, a number of the process evaluations and redesigns were seen as having provided important contributions for eIT's organizational development efforts. In addition, the skills developed during this project were significant for both the students and eIT professionals. Remaining true to the course topic, the most significant benefit for eIT as an organization was the ability to develop collaborative skills. These skills fall into two categories: collaboration with academia and effective collaboration on a decentralized project team. Overall DZI and Temple University viewed this collaboration between industry and academia as a success.

\section{The outcomes of the partnership in the eyes of the participants}

When asked to rate their agreement with the statement "Overall, this is one of the best courses I have had at Temple", 58 percent of the students responded "Strongly agree" (the highest level of agreement); all the remaining students responded "Agree somewhat". The average rating for this question was 3.52 out of $4(0=$ strongly disagree, $4=$ strongly agree $)$. Several students pointed out that the course had required much more time and effort from them than traditional courses, which was the reason some students did not rate the course as their "best ever" in the "Strongly agree" category.

A survey was sent to all the eIT project participants and received a 50\% return. The results were interesting and suggested a variance in satisfaction between eIT management and eIT staff. While the CIO and DZI's project manager clearly felt that the project was successful as a whole, the eIT staff members differentiated between the content outcomes and the intangible outcomes. Overall the intangible outcomes of exposure to new talent, gaining process design skills, focusing attention on eIT's processes, etc. were ranked high. There was however, expectation by the process owners that the redesigns would be applied to the processes during the course partnership, which was impossible due to the nature and scope of the process changes, requiring several additional months to be implemented. After all, the process owners had to spend a considerable amount of time and effort in order to participate, and the combination of this with the fact that the process redesigns were not implemented during the course was a source of mild dissatisfaction.

\section{Lessons learned}

\section{Information sharing among teams does not ensure integration}

One of the key lessons learned regarding the use of the Web site is that, even though all the documentation generated by each team was available to all the other teams, process redesign and implementation proposals were developed in relative isolation.

The evidence gathered during the action research study strongly suggests that most teams monitored the work of the other teams through the Web site, by reading team-specific bulletin boards and documents, and even posting comments and suggestions for other teams. However, it seems that the use of that information was restricted to monitoring purposes, so teams would know, for example, if what they were doing was "as good as" what other teams were doing.

This result is in some ways similar to that of an experimental study conducted by Dennis (1996), which found that even 
though some collaboration technologies may lead users to more information, they may not ensure that the users effectively use the information available. This may be due to information overload (Casey, 1982; Chervany and Dickson, 1974; Kock, 1999a; Meyer et al., 1997; O'Reilly, 1980). That is, even though enough information about the work of each team was available to all teams, their members were not able to effectively process it, probably due to time constraints. This may also explain the fact that even though DZI's CIO had full access to the Web site, he preferred to be briefed about the main outcomes through a face-to-face project review meeting.

\section{The combined use of online and face-to-face interaction modes is better than having either only one or the other mode of communication}

The evidence from the action research study suggests that the online interaction is preferable for certain communication and coordination activities than face-to-face interaction, and viceversa. The combined used of the two modes of communication was seen as a major factor in ensuring the success of the course partnership. The following quote, from a manager directly involved in the partnership, illustrates many of the participants' views regarding this:

It was fantastic how effectively the combination of online discussion and in-person meetings and reviews melded to create a truly collaborative experience...the success of this type of project seems dependent on a blend of both the online and face-to-face interaction. Too much of either would result in a need to extend the schedule, in the case of doing all the work face-toface, or risking a lack of consensus or true teamwork/team spirit, in the case of a fully electronic experience.

This lesson is aligned with previous research findings (Kock, 1999; Kock and McQueen, 1998). However, the search for optimal combinations of communication modes suggested as relevant by this study is in stark contrast with most of the academic research on collaboration technologies in the 1980s and 1990s, which have focused on experimental comparisons between computer-mediated and face-to-face communication (Kock, 1999).

\section{The combined use of commercial Web tech- nologies and interaction norms can remove computer-mediated communication obstacles}

Our study suggests that appropriate use of commercial Webbased technologies can compensate for some of the difficulties inherent in computer-mediated communication. Several empirical studies, particularly those related to media richness theory (Daft and Lengel, 1986; Daft et al., 1987; Kock, 1998; Markus, 1994; Rice, 1992), have shown beyond much doubt that users see certain communication media other than face-

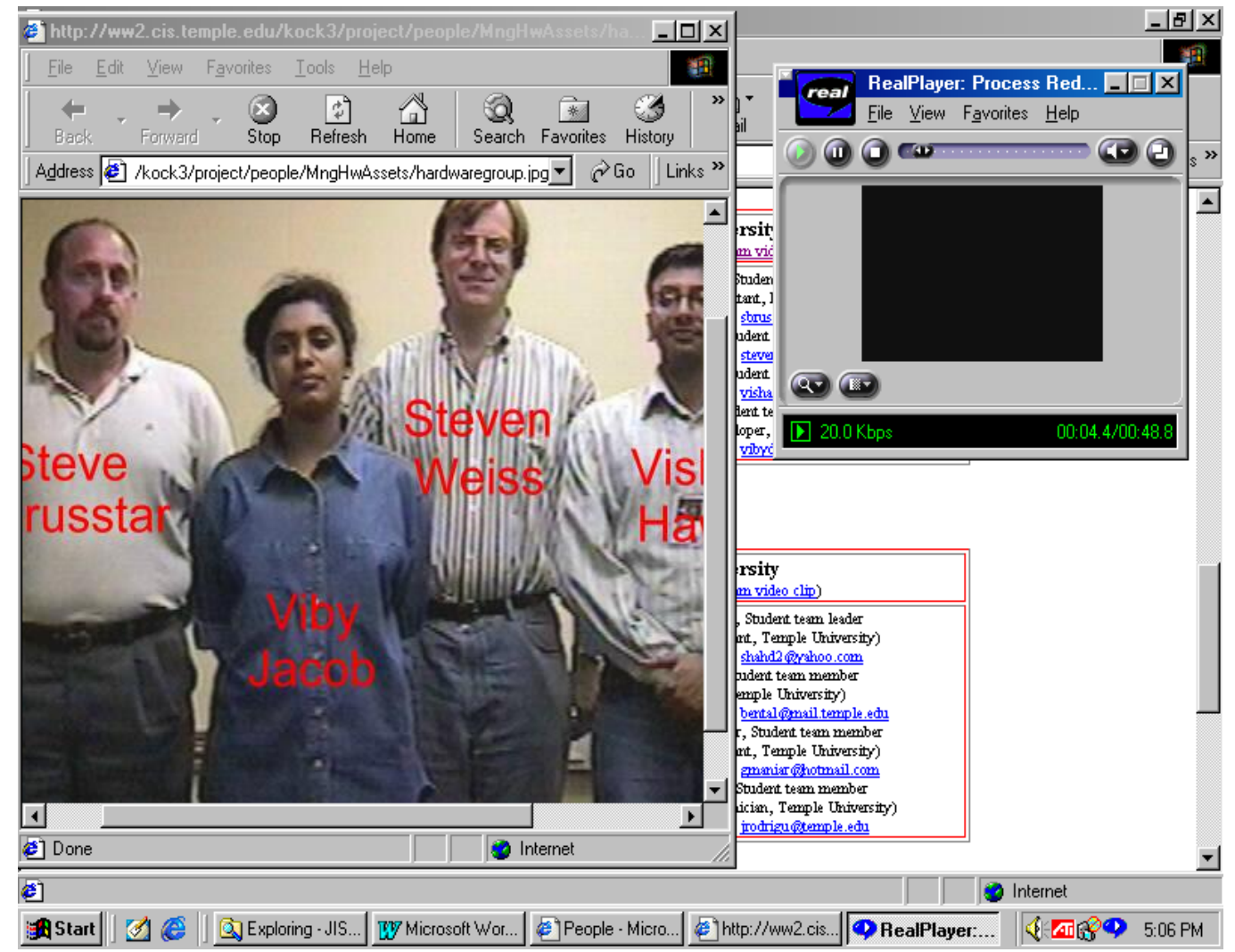

Figure 3: Images and video clips were used to mitigate the depersonalizing effect of computer-mediated communication 
to-face interaction as less appropriate for tasks as complex as process improvement. For example, computer-mediated communication is seen as depersonalizing ideas, removing non-verbal cues and preventing immediate feedback, all of which are perceived as having a negative impact on the process and outcomes of teamwork.

On the other hand, prior research findings also suggest that social and organizational norms, such as project guidelines set by management, may compensate for difficulties associated with computer-mediated communication (Markus, 1994). The action research study provides confirmation for this hypothesis. Feedback immediacy, for example, was increased by both the instructor and project manager at DZI directing the participants to check the bulletin boards available from the Web site twice a day and use them as much as possible for interaction regarding the project. As a result, over 300 postings were exchanged within a four-week period, all of which were about tasks related to the course partnership.

In addition to face-to-face meetings and communication behavior guidelines, two commercial Web-based technologies, Internet streaming and image processing, were used to mitigate the depersonalizing effect of computer-mediated communication. Video clips of the CIO, project manager, and instructor addressing important issues regarding the partnership were prepared and posted on the Web site along with video clips with team members introductions. Pictures of the team members, with names added to them, where also posted together with contact information (see Figure 3).

The amount of interaction during the course and the familiarity with which participants from Temple and eIT behaved toward each other during the pizza party is indicative of the "virtual community" sense fostered in part by behavioral norms, electronic interaction, and the multimedia components of the Web site.

\section{Conclusion}

This paper discussed a course partnership involving Day and Zimmermann, Inc. (DZI), a large engineering and professional services company headquartered in Philadelphia, and Temple University, a public university with its main campus located also in Philadelphia. The course was taught in the First Summer Session of 1999, between the months of May and July. The main goal of the course was to teach students business process redesign concepts and techniques, which were used to redesign five business processes from DZI's information technology organization. DZI's CIO and a senior manager, who played the key role of project manager, championed the course partnership within DZI. A Web site with bulletin boards, multimedia components and static content was used to support the partnership.
Our experience indicates that, given the communication and coordination difficulties associated with such partnerships, the development of a Web site with the features of the one described here is likely to be a key success factor in similar initiatives. Even though the research literature suggests a number of difficulties associated with conducting projects with the characteristics described, it has been our experience that the combined use of Web-based collaboration technologies with appropriate communication behavior norms and face-to-face interaction is likely to contribute to the success of such projects.

Overall, we believe that the benefits of course partnerships such as the one described here far outweigh their costs. However, we also identified some difficulties that are likely to be faced in similar initiatives. The work of different teams, even when shared among all the participants of the partnership, may not be easy to integrate if synergy is not set as a key goal of the project. Moreover, even though course partnerships may offer several benefits in the eyes of upper management, they may place undesirable pressure on staff who interact directly with students. These problems can be addressed by setting integration of the outcomes of different teams as a key goal of the partnership, as well as building special rewards into the project for the staff involved and those who are able to demonstrate high levels synergy.

\section{References}

Brannock, J.C. (1998), Basic Guidelines for University-industry Research Relationships, SRA Journal, V.30, No.1/2, pg. 57-63.

Burnham, J.B. (1997), Evaluating Industry-university Research Linkages, Research Technology Management, V.40, No.1; pp. 52-56.

Cabral, R. (1998), From University-industry Interfaces to the Making of a Science Park: Florianopolis, Southern Brazil, International Journal of Technology Management, V.15, No.8; pp. 778-800.

Casey, C.J. (1982), Coping with Information Overload: The Need for Empirical Research, Cost and Management, V.56, No.4, pp. 31-38.

Checkland, P. (1991), From Framework through Experience to Learning: The Essential Nature of Action Research, Information Systems Research: Contemporary Approaches and Emergent Traditions, Nissen, H., Klein, H.K. and Hirschheim, R. (Eds), North-Holland, New York, NY, pp. 397-403.

Chervany, N. and Dickson, G. (1974), An Experimental Evaluation of Information Overload in a Production Environment, Management Science, V.20, No.10. pp. 1335-1344.

Daft, R.L. and Lengel, R.H. (1986), Organizational Information Requirements, Media Richness and Structural Design, Management Science, V.32, No.5, pp. 554-571.

Daft, R.L., Lengel, R.H. and Trevino, L.K. (1987), Message Equivocality, Media Selection, and Manager Performance: Implications for Information Systems, MIS Quarterly, V.11, No.3, pp. 355-366. 
Davenport, T.H. (1993), Process Innovation, Harvard Business Press, Boston, MA.

Davenport, T.H. and Short, J.E. (1990), The New Industrial Engineering: Information Technology and Business Process Redesign, Sloan Management Review, V.31, No.4, pp. 11-27.

Dennis, A.R. (1996), Information Exchange and Use in Group Decision Making: You Can Lead a Group to Information, but You Can't Make It Think, MIS Quarterly, V.20, No.4, December, pp. 433455.

Elden, M. and Chisholm, R.F. (1993), Emerging Varieties of Action Research, Human Relations, V.46, No.2, pp. 121-141.

Greenwood, D.J., W.F. Whyte and I. Harkavy (1993), Participatory Action Research as a Process and as a Goal, Human Relations, V. 46, No. 2, pp. 175-191.

Hammer, M. and Champy, J. (1993), Reengineering the Corporation, Harper Business, New York, NY.

Harrington, H.J. (1991), Business Process Improvement, McGraw-Hill, New York, NY.

Hollingsworth, P. (1998), Economic Reality Drives Industry-university Alliances, Food Technology, Chicago, V.52, No.7; pp. 58-62.

Jonsonn, S. (1991), Action Research, Information Systems Research: Contemporary Approaches and Emergent Traditions, Nissen, H., Klein, H.K. and Hirschheim, R. (Eds), North-Holland, New York, NY, pp.371-396.

Jones-Evans, D. (1999), Creating a Bridge Between University and Industry in Small European Countries: The Role of the Industrial Liaison Office, $R \& D$ Management, V.29, No.1, pp. 47-57.

Kock, N. (1998), Can Communication Medium Limitations Foster Better Group Outcomes? An Action Research Study, Information \& Management, V.34, No.5, pp. 295-305.

Kock, N. (1999), Process Improvement and Organizational Learning: The Role of Collaboration Technologies, Idea Group Publishing, Hershey, PA.

Kock, N. (1999a), Information Overload in Organizational Processes: A Study of Managers and Professionals' Perceptions, Proceedings of the $10^{\text {th }}$ Information Resources Management International Conference, Khosrowpour, M. (Ed), Idea Group Publishing, Hershey, PA, pp. 313-320.

Kock, N. and McQueen, R.J. (1998), An Action Research Study of Effects of Asynchronous Groupware Support on Productivity and Outcome Quality of Process Redesign Groups, Journal of Organizational Computing and Electronic Commerce, V.8, No.2, pp. 149-168.

Lau, F. (1997), A Review on the Use of Action Research in Information Systems Studies, Information Systems and Qualitative Research, Lee, A.S., Liebenau, J. and DeGross, J.I. (Eds), Chapman \& Hall, London, England, pp. 31-68.
Lee, Y.S. (1998), University-industry Collaboration on Technology Transfer: Views from the Ivory Tower, Policy Studies Journal, V.26, No.1, pp. 69-85.

Markus, M.L. (1994), Electronic Mail as the Medium of Managerial Choice, Organization Science, V.5, No.4, pp. 502-527.

McTaggart, R. (1991), Principles for Participatory Action Research, Adult Education Quarterly, V.41, No.3, pp.168-187.

Mengoni, L. (1998), Cooperation between University and Industries in Organizing a 'Diploma Universitario' Curriculum: The Politecnico di Milano-Assolombarda Experience, European Journal of Engineering Education, V. 23, No.4, pp. 423-430.

Meyer, M.E., Sonoda, K.T. and Gudykunst, W.B. (1997), The Effect of Time Pressure and Type of Information on Decision Quality, The Southern Communication Journal, V.62, No.4, pp. 280-292.

Meyer-Krahmer, F. (1998), Science-based Technologies: Universityindustry Interactions in Four Fields, Research Policy, V.27, No.8; pp. 835-852.

O'Reilly, C.A. (1980), Individuals and Information Overload in Organizations: Is More Necessarily Better?, Academy of Management Journal, V.23, No.4, pp. 684-696.

Peters, M. and Robinson, V. (1984), The Origins and Status of Action Research, The Journal of Applied Behavioral Science, V.20, No.2, pp. 113-124.

Rapoport, R.N. (1970), Three Dilemmas in Action Research, Human Relations, V.23, No.6, pp. 499-513.

Rice, R.E. (1992), Task Analyzability, Use of New Media, and Effectiveness: A Multi-Site Exploration of Media Richness, Organization Science, V.3, No.4, pp. 475-500.

Saegusa, A. (1997), Japan Ties the Industry-university Knot, Nature, V.390, No.6656, p. 105.

Sommer, R. (1994), Serving Two Masters, The Journal of Consumer Affairs, V.28, No.1, pp. 170-187.

Winter, R. (1989), Learning from Experience: Principles and Practice in Action-Research, The Falmer Press, New York, NY.

Wheaton, Q. (1998), Government-University-Industry Cooperation: Does it Work?, Quality, V.37, No.5, pp. 20-24.

Whyte, W.F. (Ed) (1991), Participatory Action Research, Sage, Newbury Park, CA.

Wong, P. (1999), University-industry Technological Collaborations in Singapore: Emerging Patterns and Industry Concerns, International Journal of Technology Management, V.18, No.3, pp. 270-285.

Wood-Harper, A.T. (1985), Research Methods in Information Systems: Using Action Research, Research Methods in Information Systems, Mumford, E., Hirschheim, Fitzgerald, G. and Wood-Harper, A.T. (Eds), North-Holland, Amsterdam, The Netherlands, pp. 169-191. 